\title{
Efeito hormese de glyphosate em feijoeiro ${ }^{1}$
}

\author{
Juliano Costa da Silva², Orivaldo Arf $^{2}$, Gustavo Antonio Xavier Gerlach ${ }^{2}$, \\ Clarice Sayumi Kuryiama ${ }^{2}$, Ricardo Antonio Ferreira Rodrigues ${ }^{2}$
}

\section{ABSTRACT}

\section{Hormesis effect of \\ glyphosate on common bean cultivars}

Although being well-known, the hormesis effect has not yet a defined practical application on the development of agricultural technology. Thus, this study was carried out in Selvíria, Mato Grosso do Sul State, Brazil, in order to evaluate the effect of glyphosate applied at low doses $\left(0 \mathrm{~g} \mathrm{ha}^{-1}, 10 \mathrm{~g} \mathrm{ha}^{-1}\right.$, $20 \mathrm{~g} \mathrm{ha}^{-1}, 30 \mathrm{~g} \mathrm{ha}^{-1}$ and $40 \mathrm{~g} \mathrm{ha}^{-1}$ of active ingredient) on the development and yield of bean cultivars (Carioca precoce - type I, Juriti - type II and Pérola - type III), irrigated by aspersion, in the autumn/winter of 2009 and 2010. The experimental design was randomized blocks, with 15 treatments arranged in a $5 \times 3$ factorial scheme and four replications. It was possible to conclude that the 100 grains mass decreased when submitted to higher glyphosate sub doses, and that the application of glyphosate sub doses did not affect the common bean yield, when the three cultivars were evaluated altogether, however, when each cultivar was individually analyzed, an increase of up to $10 \%$ in yield was observed for the Juriti cultivar.

KEY-WORDS: Phaseolus vulgaris L.; herbicide; common bean cultivars.

\section{INTRODUÇÃO}

O uso de substâncias, por definição consideradas tóxicas, em doses muito menores que a utilizada para estimular o desenvolvimento vegetal, é conhecido como "hormese" (Calabrese \& Baldwin 2002a).

Apesar de o fenômeno ter sido, inicialmente, observado no Século XIX, este termo foi empregado pela primeira vez em uma publicação de 1942, a qual descrevia que o crescimento de fungos submetidos a tratamento com antibiótico natural (encontrado em casca de tronco de árvore) era estimulado em baixas concentrações e suprimido sob altas concentrações (Sagan 1991).

\section{RESUMO}

Embora o efeito hormese seja amplamente conhecido, ainda não tem aplicação prática definida para o desenvolvimento da tecnologia agropecuária. Desta forma, propôs-se um estudo, no município de Selvíria (MS), com o objetivo de verificar o efeito da aplicação de baixas doses do herbicida glyphosate $\left(0 \mathrm{~g} \mathrm{ha}^{-1}, 10 \mathrm{~g} \mathrm{ha}^{-1}, 20 \mathrm{~g} \mathrm{ha}^{-1}, 30 \mathrm{~g} \mathrm{ha}^{-1}\right.$ e $40 \mathrm{~g} \mathrm{ha}^{-1}$ do ingrediente ativo) no desenvolvimento e produtividade de cultivares de feijão (Carioca precoce - tipo I, Juriti - tipo II e Pérola - tipo III) irrigadas por aspersão, no outono-inverno de 2009 e 2010 . O delineamento experimental foi em blocos casualizados, com 15 tratamentos dispostos em esquema fatorial $5 \times 3$ e quatro repetições. Concluiu-se que a massa de 100 grãos foi reduzida, quando submetida a subdoses mais elevadas de glyphosate, e que a aplicação de subdoses de glyphosate não alterou a produtividade do feijoeiro, quando avaliadas as três cultivares conjuntamente, entretanto, quando cada cultivar foi analisada individualmente, verificou-se aumento na produtividade do feijoeiro de até $10 \%$, para a cultivar Juriti.

PALAVRAS-CHAVE: Phaseolus vulgaris L.; herbicida; cultivares de feijão.

Na década de 1970, observou-se que elevadas doses de glyphosine poderiam promover a morte das plantas. A partir desta informação, foi desenvolvido um novo composto com menores dimensões moleculares e com maior afinidade à enzima EPSPS (5-enolpyruvylshikimate-3-phosphate synthase) (Halter 2009).

Inicialmente, vários herbicidas foram desenvolvidos como reguladores de crescimento, comprovando a hipótese de hormese. O exemplo mais notório é o do produto 2,4-D, originalmente desenvolvido como auxina e que, em doses elevadas, tem efeito herbicida (Mousdale \& Coggins 1991).

Outro exemplo é o próprio glyphosate, cujo antecessor, o glyphosine (utilizado no Brasil como

1. Trabalho recebido em mar./2012 e aceito para publicação em ago./2012 (nº registro: PAT 17628).

2. Universidade Estadual Paulista (Unesp), Faculdade de Engenharia, Ilha Solteira, SP, Brasil.E-mails: jcsagro@gmail.com, arf@agr.feis.unesp.br, gustavo71180@aluno.feis.unesp.br, kuriyama_cs@hotmail.com, ricardo@agr.feis.unesp.br. 
maturador), ainda é utilizado como regulador de crescimento, em vários países (Halter 2009). O glyphosate apresentou efeito de hormese em diversas plantas, como crescimento da parte aérea e radicular de $C$. bengalensis (Meschede et al. 2007), aumento de matéria verde em milho (Wagner et al. 2003), crescimento inicial em cana-de-açúcar (Silva et al. 2009) e teor de fósforo nas folhas de eucalipto (Carbonari et al. 2007).

Um exame de hormese em plantas cultivadas e em plantas silvestres tratadas com baixas doses de herbicidas revela que o incremento na variável analisada pode ser de poucos pontos percentuais a saltos superiores a $100 \%$ (Cedergreen et al. 2005). Os estímulos em culturas de cana-de-açúcar, soja, milho, cevada, centeio, eucalipto e pinheiro são verificados em características de crescimento, como ganho de peso, altura, comprimento e área foliar, e/ ou características internas, como teor proteico e níveis de açúcares. Na maior parte deles, os herbicidas empregados nos testes foram o MSMA, oxifluorfen, terbacil, simazine e glyphosate, com citações de trabalhos clássicos da década de 1960 a trabalhos atuais, como o de Duke et al. (2006). Estes estudos sugerem que o efeito hormese pode se tornar uma alternativa a ser empregada no sistema produtivo do feijoeiro e na agricultura em geral.

O glifosato ( $\mathrm{N}$-fosfonometilglicina) é hoje o herbicida mais utilizado no Brasil e no mundo (Bastos \& Simoni 2010). É componente fundamental da grande maioria dos sistemas de produção agrícola. Trata-se de um herbicida de aplicação em pós-emergência das plantas, pertencente ao grupo químico das glicinas substituídas, classificado como não-seletivo e de ação sistêmica, que atua na inibição da EPSPS. Possui largo espectro de ação, que possibilita excelente controle de plantas daninhas anuais ou perenes, tanto de folhas largas quanto estreitas (Galli \& Montezuma 2005).

A inibição da enzima EPSPS pelo glyphosate resulta no acúmulo de chiquimato nos vacúolos. Este acúmulo leva à perda de controle da retroalimentação do fluxo de carbono, na rota do chiquimato. Esta rota é responsável por, aproximadamente, $35 \%$ da matéria seca da planta e $20 \%$ do carbono fixado pela fotossíntese derivada desta rota (Gazziero \& Prete 2004).

Com exceção de algumas variedades de plantas transgênicas, todas as plantas são sensíveis ao glyphosate, em maior ou menor intensidade, indicando uma variabilidade funcional nos pontos de ligação dos compostos com a enzima EPSPS. Vários estudos têm demonstrado que o uso de glyphosate, em pequenas doses, pode vir a estimular um ganho na massa seca de plantas, tirosina e caroteno, além de aumento na absorção de fósforo (Godoy 2007). No entanto, pouco se sabe sobre seus efeitos nos componentes de produção, assim como na produtividade de grãos, em plantas cultivadas, como ocorre na cultura do feijão.

Assim, este trabalho objetivou avaliar o efeito da aplicação de subdoses de glyphosate no desenvolvimento de componentes de produção e produtividade de cultivares de feijoeiro com diferentes hábitos de crescimento.

\section{MATERIAL E MÉTODOS}

O experimento foi desenvolvido no período de outono-inverno dos anos de 2009 e 2010, em área experimental da Fazenda de Ensino e Pesquisa da Faculdade de Engenharia da Universidade Estadual Paulista, Campus de Ilha Solteira, em Selvíria (MS). Segundo Centurion (1982), a precipitação total anual no local é de $1.330 \mathrm{~mm}$, a temperatura média anual de, aproximadamente, $25^{\circ} \mathrm{C}$ e a média anual de umidade relativa do ar de $66 \%$. O solo do local é classificado como Latossolo Vermelho distrófico típico argiloso (Embrapa 2006).

Antes da instalação dos experimentos, o solo do local foi amostrado, na camada 0,00-0,20 m, e os resultados da análise de fertilidade do solo, segundo método descrito em Raij \& Quaggio (1983), foram: $\mathrm{P}$ (resina) $=17 \mathrm{mg} \mathrm{dm}^{-3} ; \mathrm{MO}=$ $13 \mathrm{~g} \mathrm{dm}^{-3} ; \mathrm{pH}(\mathrm{CaCl} 2)=5,2 ; \mathrm{K}=0,29 \mathrm{cmol}_{\mathrm{c}} \mathrm{dm}^{-3}$; $\mathrm{Ca}=3,3 \mathrm{cmol} \mathrm{dm}^{-3} ; \mathrm{Mg}=1,4 \mathrm{cmol}_{\mathrm{c}} \mathrm{dm}^{-3} ; \mathrm{H}+\mathrm{Al}=$ $2,7 \mathrm{cmol}_{\mathrm{c}} \mathrm{dm}^{-3} ; \mathrm{Al}=0,0 \mathrm{cmol}_{\mathrm{c}} \mathrm{dm}^{-3} ; \mathrm{SB}=5,0 \mathrm{cmol}_{\mathrm{c}} \mathrm{dm}^{-3}$; $\mathrm{CTC}=7,7 \mathrm{cmol}_{\mathrm{c}} \mathrm{dm}^{-3} ; \mathrm{V}=65 \%$.

Em ambos os anos, o experimento foi instalado em áreas com sistema de cultivo convencional, anteriormente ocupadas com a cultura do arroz, nas quais realizou-se preparo do solo com aração e gradagem. Logo após a aração, foi realizada uma gradagem de nivelamento e, pouco antes da semeadura, a gradagem final, com o objetivo de eliminar plantas daninhas em início de desenvolvimento.

O delineamento experimental, em ambos os anos, foi o de blocos casualizados, com 15 tratamentos dispostos em esquema fatorial $5 \times 3$. Os tratamentos foram constituídos pela combinação de subdoses de glyphosate $\left(0 \mathrm{~g} \mathrm{ha}^{-1}, 10 \mathrm{~g} \mathrm{ha}^{-1}, 20 \mathrm{~g} \mathrm{ha}^{-1}, 30 \mathrm{~g} \mathrm{ha}^{-1}\right.$ 
e $40 \mathrm{~g} \mathrm{ha}^{-1}$ do i.a.) e cultivares de feijão (Carioca precoce - tipo I, Juriti - tipo II e Pérola - tipo III), com quatro repetições. As parcelas experimentais foram constituídas por cinco linhas de 4,5 m de comprimento, espaçadas $0,50 \mathrm{~m}$ entre si, perfazendo área total de $11,25 \mathrm{~m}^{2}$ e área útil de $5,25 \mathrm{~m}^{2}$, uma vez que, para a coleta dos dados, foram utilizadas as três linhas centrais, desprezando-se $0,50 \mathrm{~m}$ da extremidade de cada uma delas.

A semeadura do feijão foi feita manualmente, nos dias 29 de abril de 2009 e 04 de maio de 2010, utilizando-se as três cultivares e distribuindo-se as sementes em quantidades suficientes para obtenção de 12-13 plantas $\mathrm{m}^{-1}$.

A adubação química básica nos sulcos de semeadura foi constituída de $250 \mathrm{~kg} \mathrm{ha}^{-1}$ da fórmula 08-28-16, nos dois anos de cultivo. Após a semeadura, a área foi irrigada, para favorecer a germinação e emergência. A emergência ocorreu aos sete dias após a semeadura, nos dias 06 de maio de 2009 e 11 de maio de 2010.

O fornecimento de água foi proporcionado por um sistema de irrigação por aspersão fixo, com vazão de $3,3 \mathrm{~mm} \mathrm{~h}^{-1}$ nos aspersores, sendo a quantidade de água calculada de acordo com a evapotranspiração da cultura.

$\mathrm{Na}$ fase $\mathrm{V}_{4-3}$ de desenvolvimento do feijoeiro, aos 20 dias após a emergência das plantas, foi realizada, manualmente, adubação nitrogenada em cobertura, na dose de $80 \mathrm{~kg} \mathrm{ha}^{-1}$ de nitrogênio, utilizando-se, como fonte, o sulfato de amônio, com o intuito de reduzir as perdas deste elemento por volatilização.

A aplicação do glyphosate foi realizada em forma de pulverização foliar, aos 25 dias após a emergência, quando as plantas estavam no estádio $\mathrm{V}_{4-4}$ (quarta folha trifoliada completamente formada), com o auxílio de um pulverizador costal pressurizado a $\mathrm{CO}_{2}$, dotado de barra com cinco pontas espaçadas em $0,50 \mathrm{~m}$, modelo TXA $8002 \mathrm{VK}$, operado à pressão de $3 \mathrm{kgf} \mathrm{pol}^{-2}$, com volume de calda de $160 \mathrm{~L} \mathrm{ha}^{-1}$. Em ambos os anos de cultivo, a aplicação do glyphosate foi realizada em horário com temperaturas mais amenas (final de tarde) e baixa interferência do vento.

As plantas daninhas foram controladas em pós-emergência, utilizando-se os herbicidas fluazifop-p-butil + fomesafen $\left(120+150 \mathrm{~g} \mathrm{ha}^{-1}\right.$, respectivamente). A aplicação foi realizada quando a cultura encontrava-se no estádio de desenvolvimento $\mathrm{V}_{3-4} \mathrm{e}$ as plantas daninhas em estádios iniciais de desenvolvimento, para ambos os anos de cultivo. O manejo dos principais insetos-praga e doenças foi realizado por meio de pulverizações com produtos registrados para a cultura e específicos para cada caso.

O florescimento pleno médio das plantas das cultivares Carioca precoce, Juriti e Pérola ocorreu nos dias 08,19 e 21 de junho de 2009, respectivamente aos 33, 44 e 46 dias após a emergência das plantas, para o primeiro ano de cultivo. No segundo ano de cultivo, o florescimento médio das cultivares Carioca precoce, Juriti e Pérola ocorreu nos dias 13, 23 e 26 de junho de 2010, respectivamente aos 33, 43 e 46 dias após a emergência das plantas.

A colheita ocorreu nos dias 23 de julho de 2009, para a cultivar Carioca precoce, e 03 de agosto de 2009, para as cultivares Juriti e Pérola, respectivamente aos 78 e 89 dias após a emergência das plantas, no primeiro ano de cultivo, e nos dias 09 de agosto de 2010, para cultivar Carioca precoce, e 15 de agosto de 2010, para as cultivares Juriti e Pérola, respectivamente aos 90 e 96 dias após a emergência das plantas, no segundo ano de cultivo, sendo colhidas três linhas centrais de 3,50 m de comprimento.

Por ocasião da colheita, foram coletadas 10 plantas, em local pré-determinado, na área útil de cada parcela, as quais foram levadas ao laboratório, para avaliação da altura de planta, altura de inserção da primeira vagem, comprimento da primeira vagem, número de vagens planta ${ }^{-1}$, número de grãos planta ${ }^{-1}$ e número de grãos vagem ${ }^{-1}$. Avaliou-se, também, a massa de 100 grãos, determinada pela coleta ao acaso e pesagem de duas amostras de 100 grãos por parcela, e, por fim, a produtividade de grãos, com as plantas da área útil de cada parcela sendo arrancadas e secas a pleno sol. Após a secagem, as mesmas foram submetidas a trilha mecânica e, posteriormente, os grãos foram pesados e os dados transformados em $\mathrm{kg} \mathrm{ha}^{-1}$ (13\% base úmida).

Os dados foram analisados utilizando-se o programa Sisvar (Ferreira 2000) e as médias comparadas pelo teste Tukey, para as cultivares, e regressão, para as doses de glyphosate.

\section{RESULTADOS E DISCUSSÃO}

Constatou-se que houve diferença significativa para altura de plantas e altura de inserção da primeira vagem, em 2009, entre as cultivares avaliadas, porém, neste ano, não ocorreu diferença significativa para o comprimento das vagens. Já em 2010, isto ocorreu para as três variáveis em questão (Tabela 1). 
Estes resultados ocorreram, provavelmente, por se tratarem de características genéticas relacionadas a cada cultivar. Quanto às subdoses de glyphosate, os resultados não foram significativos para nenhum modelo ajustado, para as três variáveis analisadas em ambos os anos de cultivo (Tabela 1).

A altura de plantas é uma variável bastante observada na literatura, em trabalhos referentes ao efeito hormese. Neste estudo, os resultados referentes às doses de glyphosate não se ajustaram a nenhum modelo testado, porém, observou-se uma pequena retomada no crescimento, a partir da dose de $40 \mathrm{~g} \mathrm{ha}^{-1}$ do i.a., para os dois anos de cultivo.

Utilizando-se de outro modelo estatístico, Neves et al. (2009), em estudo com algodoeiro, observaram estímulo de $15 \%$ para essa variável, em relação à testemunha, nas doses de 18-33,5 $\mathrm{g} \mathrm{ha}^{-1}$ do i.a., com máxima resposta de $16,4 \%$, na dose de $27 \mathrm{~g} \mathrm{ha}^{-1}$ do i.a. (correspondente a $75 \mathrm{~mL}$ do produto comercial). O mesmo não ocorreu em mudas de urucuzeiro estudadas por Soares et al. (2010), já que o aumento nas subdoses de glyphosate proporcionou efeito inversamente proporcional ao crescimento das mudas.

Velini et al. (2008) verificaram ganho na biomassa da parte aérea e aumento no número de ramos laterais, em mudas de eucalipto, a partir da dose de $3,6 \mathrm{~g} \mathrm{ha}^{-1}$ do ingrediente ativo. Também com euca- lipto, Carbonari et al. (2007) concluíram que baixas doses de glyphosate (3,6-7,2 $\mathrm{g} \mathrm{ha}^{-1}$ do i.a.) afetaram positivamente o crescimento das plantas, aumentando $\mathrm{a}$ área foliar e biomassa. Estes incrementos no crescimento são mais acentuados em plantas submetidas à maior disponibilidade de fósforo no solo. Tais resultados corroboram os observados por Meschede et al. (2007), os quais verificaram que, em geral, doses a partir de $2 \mathrm{~g} \mathrm{ha}^{-1}$ do i.a. de glyphosate são capazes de causar efeitos no crescimento e desenvolvimento da parte aérea e radicular de plantas de $C$. bengalensis (capim trapoeraba).

Godoy (2007) estudou o efeito de subdoses de glyphosate nas cultivares de soja BRS 232 (não resistente ao glyphosate) e BRS 243 (resistente ao glyphosate) e observou que houve estímulos ao crescimento das plantas, para doses de 3,6-36 $\mathrm{g} \mathrm{ha}^{-1}$ do i.a., sobre a cultivar de soja convencional BRS 232. Silva et al. (2009) obtiveram estímulos nas características de crescimento e no desenvolvimento inicial em cana-de-açúcar, com a subdose de $1,8 \mathrm{~g} \mathrm{ha}^{-1}$ do i.a.

Para o número de vagens por planta, número de grãos por planta e número de grãos por vagem (Tabela 2), pôde-se observar que não houve diferença significativa entre as cultivares, no ano de 2009, porém, o mesmo não ocorreu no ano seguinte, quando houve diferença significativa para as três variáveis analisadas. No ano de 2010, a cultivar Juriti apre-

Tabela 1. Valores médios de altura de plantas, altura de inserção da primeira vagem e comprimento da primeira vagem obtidos em feijoeiro de inverno irrigado, em função de cultivares e subdoses de glyphosate (Selvíria, MS, 2009/2010).

\begin{tabular}{|c|c|c|c|c|c|c|}
\hline \multirow{2}{*}{ Tratamentos } & \multicolumn{2}{|c|}{ Altura de plantas } & \multicolumn{2}{|c|}{$\begin{array}{c}\text { Altura de inserção de } \\
\text { vagens }\end{array}$} & \multicolumn{2}{|c|}{ Comprimento de vagens } \\
\hline & 2009 & 2010 & 2009 & 2010 & 2009 & 2010 \\
\hline Cultivares & \multicolumn{6}{|c|}{$-\mathrm{cm}$} \\
\hline Carioca precoce & $75,90 \mathrm{~b}$ & $44,70 \mathrm{c}$ & $12,50 \mathrm{a}$ & $11,25 \mathrm{a}$ & 9,88 & $8,59 \mathrm{~b}$ \\
\hline Juriti & $113,20 \mathrm{a}$ & $65,82 \mathrm{~b}$ & $9,52 \mathrm{~b}$ & $9,51 \mathrm{~b}$ & 9,91 & $9,02 \mathrm{ab}$ \\
\hline Pérola & $113,30 \mathrm{a}$ & $80,66 \mathrm{a}$ & $9,84 \mathrm{~b}$ & $11,13 \mathrm{a}$ & 10,24 & $9,52 \mathrm{a}$ \\
\hline \multicolumn{7}{|c|}{ Doses de glyphosate ( $\mathrm{g} h \mathrm{a}^{-1}$ do i.a.) } \\
\hline 0 & 103,59 & 64,05 & 10,57 & 9,89 & 10,14 & 9,24 \\
\hline 10 & 99,23 & 62,30 & 10,53 & 10,60 & 10,00 & 9,10 \\
\hline 20 & 99,80 & 63,60 & 10,73 & 11,49 & 10,13 & 8,67 \\
\hline 30 & 100,92 & 61,74 & 10,16 & 10,00 & 9,98 & 8,98 \\
\hline \multirow[t]{2}{*}{40} & 100,61 & 66,94 & 11,10 & 11,18 & 9,81 & 9,25 \\
\hline & \multicolumn{6}{|c|}{ Valores de F } \\
\hline Cultivar (C) & $43,28 * *$ & $108,73 * *$ & $8,91 * *$ & $4,51^{*}$ & $1,97^{\mathrm{ns}}$ & $5,95 * *$ \\
\hline Dose (D) & $0,16^{\mathrm{ns}}$ & $0,82^{\mathrm{ns}}$ & $0,23^{\mathrm{ns}}$ & $1,41^{\mathrm{ns}}$ & $0,53^{\mathrm{ns}}$ & $0,92^{\text {ns }}$ \\
\hline $\mathrm{C} * \mathrm{D}$ & $0,62^{\text {ns }}$ & $1,92^{\text {ns }}$ & $0,99^{\text {ns }}$ & $1,03^{\mathrm{ns}}$ & $0,71^{\mathrm{ns}}$ & $1,39^{\mathrm{ns}}$ \\
\hline DMS Cultivar & 11,28 & 5,96 & 1,89 & 1,57 & - & 0,66 \\
\hline $\mathrm{CV}(\%)$ & 14,56 & 12,16 & 23,13 & 19,28 & 6,42 & 9,48 \\
\hline
\end{tabular}

Médias seguidas da mesma letra, nas colunas, não diferem estatisticamente entre si, pelo teste Tukey, a $5 \%$. ns Não significativo; * e ** Significativo a $5 \%$ e $1 \%$, respectivamente. 
Tabela 2. Médias de vagens planta ${ }^{-1}$, grãos planta $^{-1}$ e grãos vagem ${ }^{-1}$ em feijoeiro de inverno, em função de cultivares e subdoses de glyphosate (Selvíria, MS, 2009/2010).

\begin{tabular}{|c|c|c|c|c|c|c|}
\hline \multirow{2}{*}{ Tratamentos } & \multicolumn{2}{|c|}{ Vagens planta $^{-1}$} & \multicolumn{2}{|c|}{ Grãos planta $^{-1}$} & \multicolumn{2}{|c|}{ Grãos vagem $^{-1}$} \\
\hline & 2009 & 2010 & 2009 & 2010 & 2009 & 2010 \\
\hline \multicolumn{7}{|l|}{ Cultivares } \\
\hline Carioca precoce & 11,72 & $9,87 \mathrm{~b}$ & 55,57 & $37,74 \mathrm{~b}$ & 4,75 & $3,81 \mathrm{ab}$ \\
\hline Juriti & 13,84 & $13,38 \mathrm{a}$ & 64,13 & $47,91 \mathrm{a}$ & 4,77 & $3,56 \mathrm{~b}$ \\
\hline Pérola & 12,64 & $10,01 \mathrm{~b}$ & 65,86 & $38,91 \mathrm{~b}$ & 5,02 & $3,94 \mathrm{a}$ \\
\hline \multicolumn{7}{|c|}{ Doses de glyphosate (g hat do i.a.) } \\
\hline 0 & 13,38 & 12,20 & 65,21 & 45,91 & 4,88 & 3,78 \\
\hline 10 & 10,43 & 10,77 & 52,23 & 41,24 & 5,02 & 3,93 \\
\hline 20 & 13,54 & 11,59 & 65,74 & 42,35 & 4,82 & 3,61 \\
\hline 30 & 12,72 & 10,38 & 62,13 & 38,33 & 4,84 & 3,72 \\
\hline \multirow[t]{2}{*}{40} & 13,60 & 10,48 & 63,95 & 39,75 & 4,68 & 3,80 \\
\hline & \multicolumn{6}{|c|}{ Valores de F } \\
\hline Cultivar (C) & $2,19^{\mathrm{ns}}$ & $10,34 * *$ & $2,01^{\mathrm{ns}}$ & $4,70^{*}$ & $2,74^{\mathrm{ns}}$ & $5,19 * *$ \\
\hline Dose (D) & $2,08^{\mathrm{ns}}$ & $0,97^{\mathrm{ns}}$ & $1,23^{\mathrm{ns}}$ & $0,76^{\mathrm{ns}}$ & $1,11^{\mathrm{ns}}$ & $1,12^{\mathrm{ns}}$ \\
\hline $\mathrm{C} * \mathrm{D}$ & $1,46^{\mathrm{ns}}$ & $1,90^{\mathrm{ns}}$ & $1,29^{\text {ns }}$ & $1,71^{\mathrm{ns}}$ & $0,40^{\mathrm{ns}}$ & $1,82^{\mathrm{ns}}$ \\
\hline DMS Cultivar & - & 2,12 & - & 8,82 & - & 0,29 \\
\hline $\mathrm{CV}(\%)$ & 25,25 & 24,92 & 28,12 & 27,63 & 8,30 & 9,99 \\
\hline
\end{tabular}

Médias seguidas da mesma letra, nas colunas, não diferem estatisticamente entre si, pelo teste Tukey, a $5 \%$. ns Não significativo; * e ** Significativo a $5 \%$ e $1 \%$, respectivamente.

sentou maior número de vagens por planta e maior número de grãos por planta que as outras cultivares em questão, ficando apenas com menor número de grãos por vagem que as cultivares Carioca precoce e Pérola.

Com relação às subdoses de glyphosate, não houve influência nos resultados, em ambos os anos de cultivo, contrariando os resultados de Gitti et al. (2011), que observaram, na cultura do arroz, aumento no número de grãos totais e granados por panícula, no intervalo de subdoses entre $11,6 \mathrm{~g} \mathrm{ha}^{-1}$ e $32,0 \mathrm{~g} \mathrm{ha}^{-1}$ de glyphosate, e, com o aumento das subdoses de glyphosate, o número de panículas por $\mathrm{m}^{2}$ foi elevado, porém, sem influenciar na produtividade do arroz.

Com relação à massa de 100 grãos e à produtividade (Tabela 3), observou-se efeito significativo entre as cultivares, destacando-se a cultivar Pérola, para massa de 100 grãos, e a Juriti, para produtividade, em ambos os anos avaliados.

Quando comparadas as subdoses de glyphosate, não foi observada influência na produtividade, nos dois anos agrícolas. No entanto, em 2010, foi possível notar que as maiores subdoses de glyphosate proporcionaram decréscimo significativo na massa de 100 grãos, com os resultados obtidos ajustando-se a uma equação linear decrescente. O mesmo foi verificado por Melhorança Filho et al. (2010), na cultura da soja convencional, indicando que, à me- dida em que as doses aumentaram $\left(0 \mathrm{~g} \mathrm{ha}^{-1}, 5 \mathrm{~g} \mathrm{ha}^{-1}\right.$, $10 \mathrm{~g} \mathrm{ha}^{-1}, 15 \mathrm{~g} \mathrm{ha}^{-1}, 20 \mathrm{~g} \mathrm{ha}^{-1}, 25 \mathrm{~g} \mathrm{ha}^{-1}$ e $30 \mathrm{~g} \mathrm{ha}^{-1}$ do i.a.), ocorreu decréscimo linear na massa de grãos. Por outro lado, resultados obtidos por Magalhães et al. (2001), simulando deriva dos herbicidas glyphosate e paraquat, assim como seus efeitos no desenvolvimento das plantas e no rendimento de grãos de sorgo, demonstraram que a massa de 1.000 grãos não foi afetada pelas doses reduzidas dos herbicidas. Mesmo não sendo apontado como resultado deste mesmo trabalho, os autores apresentam gráficos que permitem observar ganhos de, aproximadamente, $400 \mathrm{~kg} \mathrm{ha}^{-1}$ na produtividade do sorgo, quando utilizadas subdoses entre $2 \%$ e $4 \%$ da dose recomendada do produto comercial.

Ao fazer uma análise isolada de cada cultivar, em resposta à aplicação das subdoses de glyphosate, é possível observar, com maior clareza, o efeito hormese no feijoeiro (Figura 1). Para tanto, foi atribuído o valor de $100 \%$ para a produtividade do tratamento testemunha (sem aplicação) e compararam-se os demais tratamentos em forma de percentagem, em relação à testemunha, referindo-se à produtividade do feijoeiro das cultivares Carioca precoce, Juriti e Pérola, de acordo com as subdoses de glyphosate, para os dois anos de cultivo.

Observou-se redução na produtividade da cultivar Carioca precoce, com o aumento das sub- 
Tabela 3. Médias da massa de 100 grãos e produtividade de grãos em feijoeiro de inverno irrigado, em função de cultivares e subdoses de glyphosate (Selvíria, MS, 2009/2010).

\begin{tabular}{|c|c|c|c|c|}
\hline \multirow[t]{2}{*}{ Tratamentos } & \multicolumn{2}{|c|}{$\begin{array}{c}\text { Massa de } 100 \text { grãos } \\
(\mathrm{g})\end{array}$} & \multicolumn{2}{|c|}{$\begin{array}{l}\text { Produtividade } \\
\quad\left(\mathrm{kg} \mathrm{ha}^{-1}\right)\end{array}$} \\
\hline & 2009 & 2010 & 2009 & 2010 \\
\hline \multicolumn{5}{|l|}{ Cultivares } \\
\hline Carioca precoce & $23,01 \mathrm{~b}$ & $22,05 \mathrm{~b}$ & $2.356 \mathrm{ab}$ & $1.376 \mathrm{c}$ \\
\hline Juriti & $23,16 \mathrm{~b}$ & $25,45 \mathrm{a}$ & $2.669 \mathrm{a}$ & $2.867 \mathrm{a}$ \\
\hline Pérola & $25,14 \mathrm{a}$ & 26,05 a & $2.203 \mathrm{~b}$ & $2.159 \mathrm{~b}$ \\
\hline \multicolumn{5}{|c|}{ Doses de glyphosate ( $g$ ha' do i.a.) } \\
\hline 0 & 24,08 & $25,17^{(1)}$ & 2.513 & 2.273 \\
\hline 10 & 23,80 & 25,25 & 2.494 & 2.338 \\
\hline 20 & 23,58 & 25,33 & 2.381 & 2.092 \\
\hline 30 & 23,52 & 23,08 & 2.269 & 1.950 \\
\hline 40 & 23,88 & 23,75 & 2.389 & 2.018 \\
\hline \multicolumn{5}{|c|}{ Valores de $F$} \\
\hline Cultivar (C) & $38,33 * *$ & $37,31 * *$ & $6,55 * *$ & $68,28 * *$ \\
\hline Dose (D) & $0,85^{\mathrm{ns}}$ & $5,14 * *$ & $0,67^{\mathrm{ns}}$ & $2,02^{\mathrm{ns}}$ \\
\hline $\mathrm{C} * \mathrm{D}$ & $1,59^{\mathrm{ns}}$ & $0,27^{\mathrm{ns}}$ & $0,53^{\mathrm{ns}}$ & $0,29^{\mathrm{ns}}$ \\
\hline DMS Cultivar & 0,66 & 1,21 & 319,68 & 309,44 \\
\hline $\mathrm{CV}(\%)$ & 3,60 & 6,44 & 17,27 & 18,91 \\
\hline
\end{tabular}

Médias seguidas da mesma letra, nas colunas, não diferem estatisticamente entre si, pelo teste Tukey, a $5 \%$. ns Não significativo; $*$ e $* *$ Significativo a $5 \%$ e $1 \%$, respectivamente. ${ }^{(1)} \mathrm{Y}=25,5092-0,0501 \times\left(\mathrm{R}^{2}=0,62\right)$.

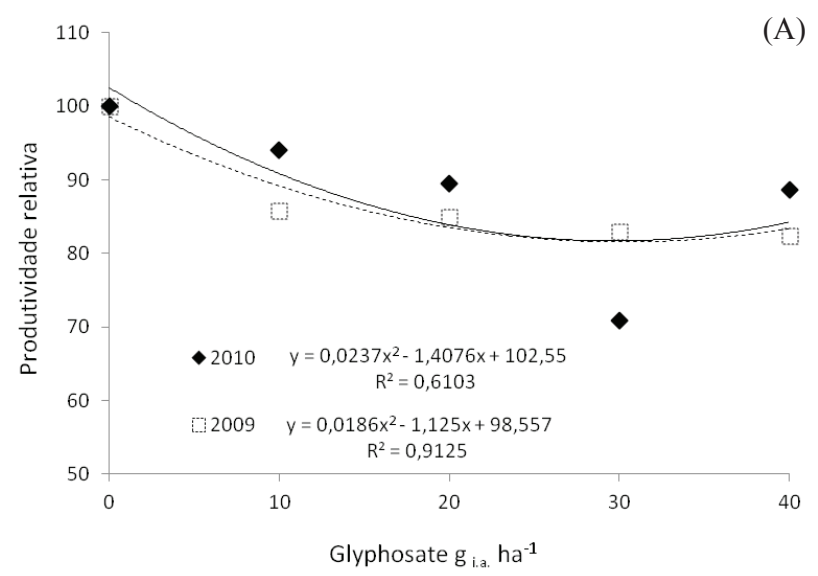

A) doses de glyphosate, para os dois anos estudados (Figura 1A). Esta cultivar foi a que apresentou maior queda na produtividade, chegando a perdas de até $25 \%$, para a dose de $30 \mathrm{~g} \mathrm{ha}^{-1}$ do i.a., em relação à testemunha sem aplicação. Desta forma, a cultivar Carioca precoce foi a mais sensível ao glyphosate, considerando-se as três cultivares avaliadas, ficando descartada a hipótese de hormese para esta cultivar.

As melhores respostas ao efeito hormese no feijoeiro foram obtidas pela cultivar Juriti (Figura 1B), que apresentou, como ponto de máxima
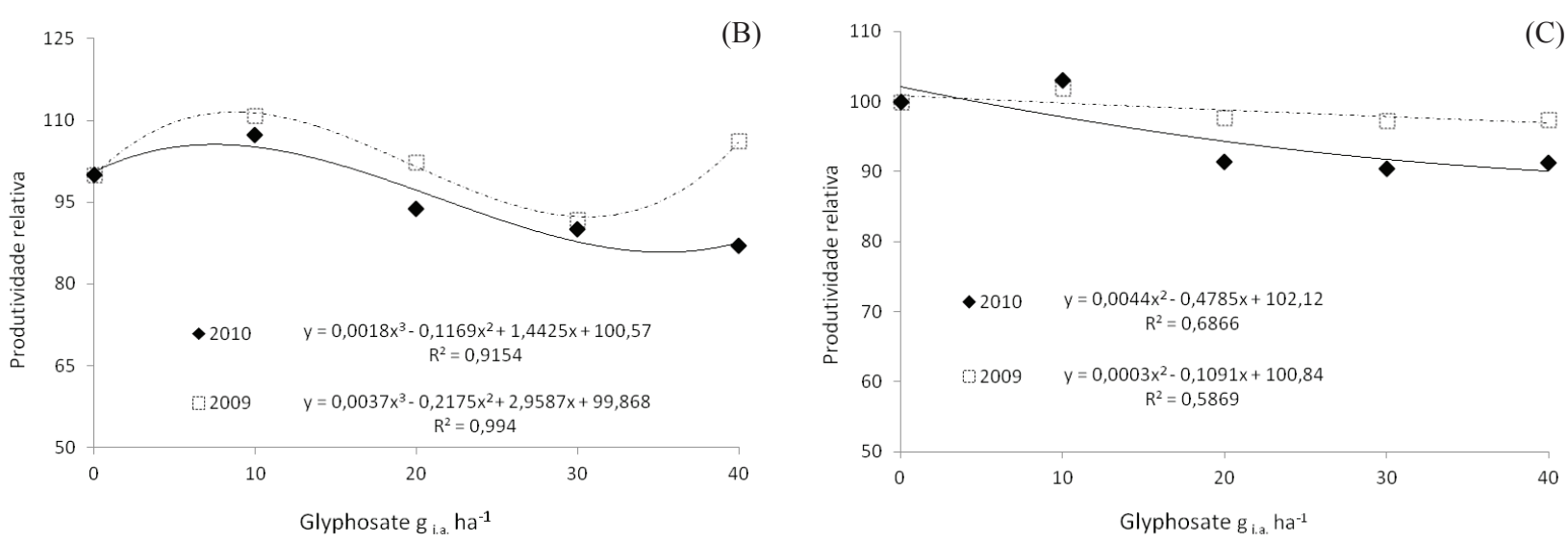

Figura 1. Produtividade relativa do feijoeiro, cultivares Carioca precoce (A), Juriti (B) e Pérola (C), em função de subdoses de glyphosate (Selvíria, MS, 2009/2010). 
resposta, a subdose de $10 \mathrm{~g} \mathrm{ha}^{-1}$ do i.a., proporcionando aumento na produtividade em torno de 7,5-10\%, em relação à testemunha sem tratamento. Este tipo de comportamento foi relatado por Calabrese \& Baldwin (2002b), sendo definido como resposta direta da cultura a baixas doses do produto.

Mesmo que de forma menos expressiva, a dose de $10 \mathrm{~g} \mathrm{ha}^{-1}$ do i.a. proporcionou aumento na produtividade da cultivar Pérola (Figura 1C), para os dois anos de cultivo, quando comparada com a testemunha sem aplicação. No entanto, a partir desta subdose, todas as demais ocasionaram redução na produtividade de grãos.

Os resultados apresentados pelas cultivares Juriti e Pérola corroboram os observados por Cedergreen et al. (2009), que obtiveram aumento na produtividade de grãos de cevada (12-15\%), com a aplicação de subdoses de glyphosate entre $2,5 \mathrm{~g} \mathrm{ha}^{-1}$ e $20 \mathrm{~g} \mathrm{ha}^{-1}$ do i.a.

\section{CONCLUSÕES}

1. Dentre os componentes de produção, a massa de 100 grãos foi reduzida com o aumento das subdoses de glyphosate.

2. De maneira geral, as subdoses de glyphosate não influenciaram na produtividade do feijoeiro, porém, a cultivar do tipo II apresentou comportamento mais responsivo ao efeito hormese.

\section{AGRADECIMENTOS}

À Fundação de Amparo à Pesquisa do Estado de São Paulo (FAPESP), pela bolsa de estudo concedida ao primeiro autor.

\section{REFERÊNCIAS}

BASTOS, A. B.; SIMONI, J. A. Determinação da variação de entalpia da interação entre o herbicida glifosato e os íons cálcio, cobre, zinco e alumínio em solução aquosa por calorimetria por titulação isotérmica. Augmdomus, La Plata, v. 2, n. 1, p. 60-71, 2010.

CALABRESE, E. J.; BALDWIN, L. A. Applications of hormesis in toxicology, risk assessment and chemotherapeutics. Trends in Pharmacological Sciences, Bruxelas, v. 23, n. 7, p. 331-337, 2002a.

CALABRESE, E. J.; BALDWIN, L. A. Defining hormesis. Human \& Experimental Toxicology, Hampshire, v. 21, n. 1, p. 91-97, 2002b.
CARBONARI, C.; MESCHEDE, D. K.; VELINI, E. D. Efeitos da aplicação de glyphosate no crescimento inicial de mudas de eucalipto submetidas a dois níveis de adubação fosfatada. In: SIMPÓSIO INTERNACIONAL SOBRE GLYPHOSATE, 1., 2007, Botucatu. Anais... Botucatu: Fepaf, 2007. p. 68-70.

CEDERGREEN, N.; RITZ, C.; STREIBIG, J. C. Improved empirical models describing hormesis. Environmental Toxicology and Chemistry, Bruxelas, v. 24, n. 12, p. 31663172, 2005.

CEDERGREEN, N. et al. Chemical stress can increase crop yield. Field Crops Research, Amsterdam, v. 114, n. 1, p. 54-57, 2009.

CENTURION, J. F. Balanço hídrico da região de Ilha Solteira. Cientifica, Jaboticabal, v. 10, n. 1, p. 57-61, 1982.

DUKE, S. O. et al. Hormesis: is it an important factor in herbicide use and allelopathy? Outlooks on Pest Management, New York, v. 17, n. 1, p. 29-33, 2006. Disponível em: <http://www.dose-response.org/news/ Hormesis-review.pdf> . Acesso em: 27 ago. 2009.

EMPRESA BRASILEIRA DE PESQUISA AGROPECUÁRIA (Embrapa). Sistema brasileiro de classificação dos solos. 2. ed. Rio de Janeiro: EmbrapaCNPS, 2006.

FERREIRA, D. F. Análises estatísticas por meio do Sisvar para Windows versão 4.0. In: REUNIÃO ANUAL DA REGIÃO BRASILEIRA DA SOCIEDADE INTERNACIONAL DE BIOMETRIA, 45., 2000, São Carlos. Programa e resumos... São Carlos: UFSCar, 2000. p. $255-258$.

GALLI, A. J. B.; MONTEZUMA, M. C. Glifosato: alguns aspectos da utilização do herbicida glifosato na agricultura. São Paulo: Acadcom, 2005.

GAZZIERO, D. L. P.; PRETE, C. E. C. Resistência é a questão. Revista Cultivar, Porto Alegre, v. 4, n. 1, p. 2224, 2004.

GITTI, D. C. et al. Glyphosate como regulador de crescimento em arroz de terras altas. Pesquisa Agropecuária Tropical, Goiânia, v. 41, n. 4, p. 500-507, 2011.

GODOY, M. C. Efeitos do glyphosate sobre o crescimento e absorção de fósforo pela soja. 2007. 53 f. Dissertação (Mestrado em Agronomia) - Faculdade de Ciências Agrárias, Universidade Estadual Paulista, Botucatu, 2007.

HALTER, S. História do herbicida agrícola glyphosate. In: VELINI, E. D. et al. Glyphosate. Botucatu: Fepaf, 2009. p. 11-16.

MAGALHÃES, P. C. et al. Efeito de doses reduzidas de glyphosate e oxofluorfen simulando deriva sobre a cultura do sorgo. Planta Daninha, Viçosa, MG, v. 19, n. 2, p. 255 262, 2001. 
MELHORANÇA FILHO, A. L. et al. Efeito de glyphosate sobre características produtivas em cultivares de soja transgênica e convencional. Bioscience Journal, Uberlândia, v. 26, n. 3, p. 322-333, 2010.

MESCHEDE, D. K.; CARBONARI, C. A.; VELINI, E. D. Efeito de subdoses de glyphosate sobre o crescimento e desenvolvimento de Commelina benghalensis. In: SIMPÓSIO INTERNACIONAL SOBRE GLYPHOSATE, 1., 2007, Botucatu. Trabalhos cientificos... Botucatu: Fepaf, 2007. p. 65-67.

MOUSDALE, D. M.; COGGINS, J. R. Amino acid synthesis. In: KIRKWOOD, R. C. Target sites for herbicide action. New York: Premium Press, 1991.

NEVES, D. C.; FURLANI JÚNIOR, E.; VALTER FILHO, $\mathrm{V}$. V. Hormese no crescimento do algodoeiro por subdoses de glifosato. In: CONGRESSO BRASILEIRO DO ALGODÃO, 7., 2009, Foz do Iguaçu. Anais... Campina Grande: Embrapa Algodão, 2009. p. 915-922.

RAIJ, B. V.; QUAGGIO, J. A. Método de análise de solo para fins de fertilidade. Campinas: Instituto Agronômico, 1983. (Boletim técnico, 81).
SAGAN, L. A. Radiation hormesis: evidence for radiation stimulation and speculation regarding mechanisms. Radiation Physics and Chemistry, Melbourne, v. 37, n. 2, p. 313-317, 1991.

SILVA, M. A. et al. Efeito hormótico de glyphosate no desenvolvimento inicial de cana-de-açúcar. Bragantia, Campinas, v. 68, n. 4, p. 973-978, 2009.

SOARES, M. B. B. et al. Efeito de subdoses de glyfosate sobre o desenvolvimento inicial de plantas de urucum. In: CONGRESSO BRASILEIRO DA CIÊNCIA DAS PLANTAS DANINHAS, 27., 2010, Ribeirão Preto. Disponível em: <http://www.sbcpd.org/portal/anais/ XXVII_CBCPD/PDFs/599.pdf >. Acesso em: 21 mar. 2012.

VELINI, E. D. et al. Glyphosate applied at low doses can stimulate plant growth. Pest Management Science, London, v. 64, n. 4, p. 489-496, 2008.

WAGNER, R.; KOGAN, M.; PARADA, A. M. Phytotoxic activity of root absorbed glyphosate in corn seedlings (Zea mays L.). Weed Biology Management, Danvers, v. 3, n. 4, p. 228-232, 2003. 